\title{
Combined goblet cell carcinoid and mucinous cystadenoma of the appendix
}

\author{
R K Al-Talib, C H Mason, J M Theaker
}

Histopathology,

Southampton

University Hospitals

NHS Trust,

Southampton S09 4XY

R K Al-Talib

J M Theaker

Department of

Histopathology,

Eastbourne District

Hospital

C H Mason

Correspondence to:

Dr J M Theaker.

Accepted for publication 18 January 1995
Department of

\begin{abstract}
Two cases of combined goblet cell carcinoid and mucinous cystadenoma occurring in the appendix are reported. The histogenesis of the goblet cell carcinoid remains one of its most controversial aspects and the occurrence of both of these relatively uncommon tumours in the same organ may lend support to the unitary stem cell hypothesis on the origin of this tumour. Alternatively, this occurrence may represent an example of the adenomal carcinoma sequence.
\end{abstract}

(f Clin Pathol 1995;48:869-870)

Keywords: Goblet cell carcinoid, mucinous cystadenoma, appendix, histogenesis.

Goblet cell carcinoid is an uncommon tumour of the appendix showing features of both a carcinoid and an adenocarcinoma. ${ }^{12}$ The mucinous cystadenoma is an epithelial neoplasm which represents the appendiceal counterpart of the more common colonic adenoma. ${ }^{34}$ In this report we wish to describe the existence of both tumours within the appendices of two patients. This is an unusual occurrence which raises the possibility of a related histogenesis.

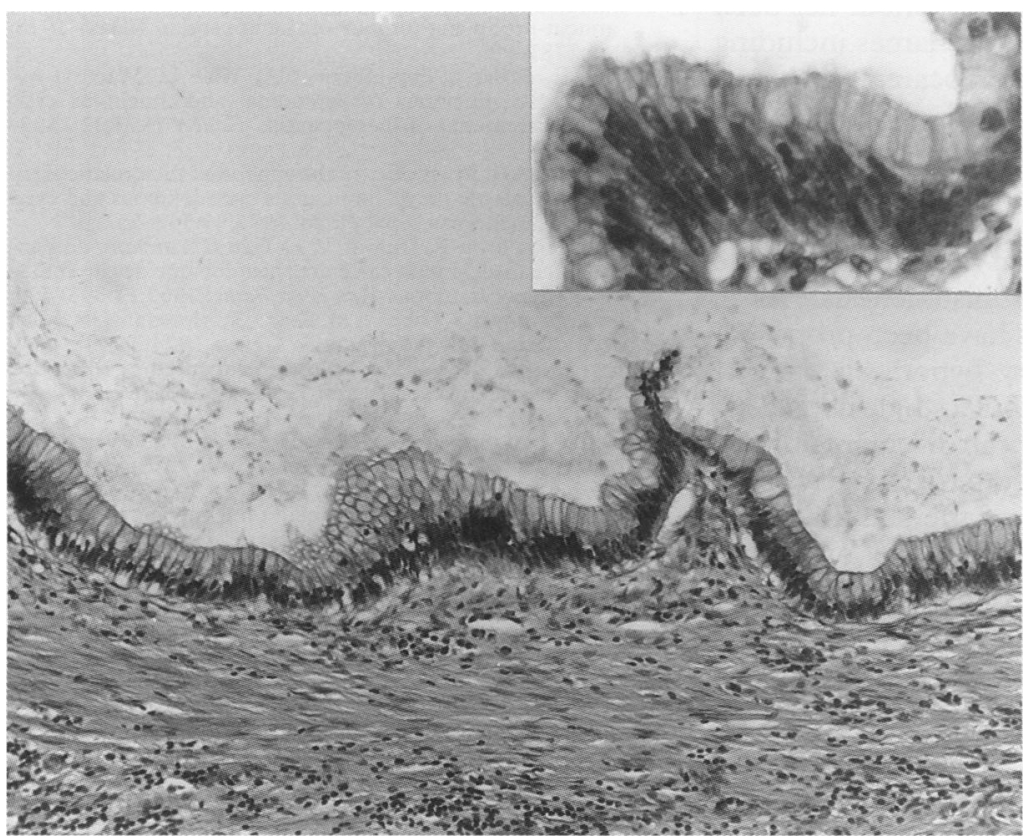

Figure 1 Mucinous cystadenoma of the appendix showing cystic dilatation of the lumen lined by mucus secreting epithelium (haematoxylin and eosin, $\times 100$ ) (inset: detail, $\times 360)$.

\section{Case reports}

CASE ONE

An adherent pelvic appendix was resected with difficulty from a 54 year old woman admitted for an interval appendicectomy, two months after an attack of appendicitis. The appendix measured $60 \times 15 \mathrm{~mm}$ and was irregular, distorted and showed serosal fibrosis. On sectioning, the tip of the appendix was distended and a mucus containing diverticulum penetrating the muscular wall of the appendix was identified.

\section{CASE TWO}

A 64 year old woman was admitted with a four month history of a dull ache in the right iliac fossa which had become increasingly severe over the last week. Eight months earlier, the patient had been admitted with a similar episode of pain which had been treated conservatively. The patient underwent appendiectomy. The resected appendix measured $65 \times 12 \mathrm{~mm}$ and had a distended, fibrotic tip which contained two small diverticulae on sectioning.

\section{Pathology}

Both appendices were of very similar appearance on histology. The diverticulae noted were produced on the basis of a mucinous cystadenoma. The lumen was focally dilatated and lined by mucus secreting columnar epithelium. The epithelium was mainly flattened with focal papillary areas. Cellular crowding with pseudo-stratification and mild to moderate atypia were noted on cytology (fig 1). The appendiceal walls were also widely infiltrated by nests, clumps and rosettes of tumour cells with features resembling those of a goblet cell carcinoid (fig 2). The tumour cells were uniform, distended with mucus and had crescentic nuclei arranged around the periphery of the tumour nests. There was little pleomorphism and mitotic activity was absent. Moderate numbers of Paneth cells, both singly and as part of the tumour nests, were present in the second case but were scarce in the first. A Gremilius stain for agyrophilia performed in case 1 revealed numerous positive cells, occurring both singly and in the periphery of small tumour trabeculae but not in the larger tumour nests. Only scattered single positive cells were identified in the second case. The tumour nests in both cases appeared to arise from the basiglandular region of the intestinal crypts, in close proximity 


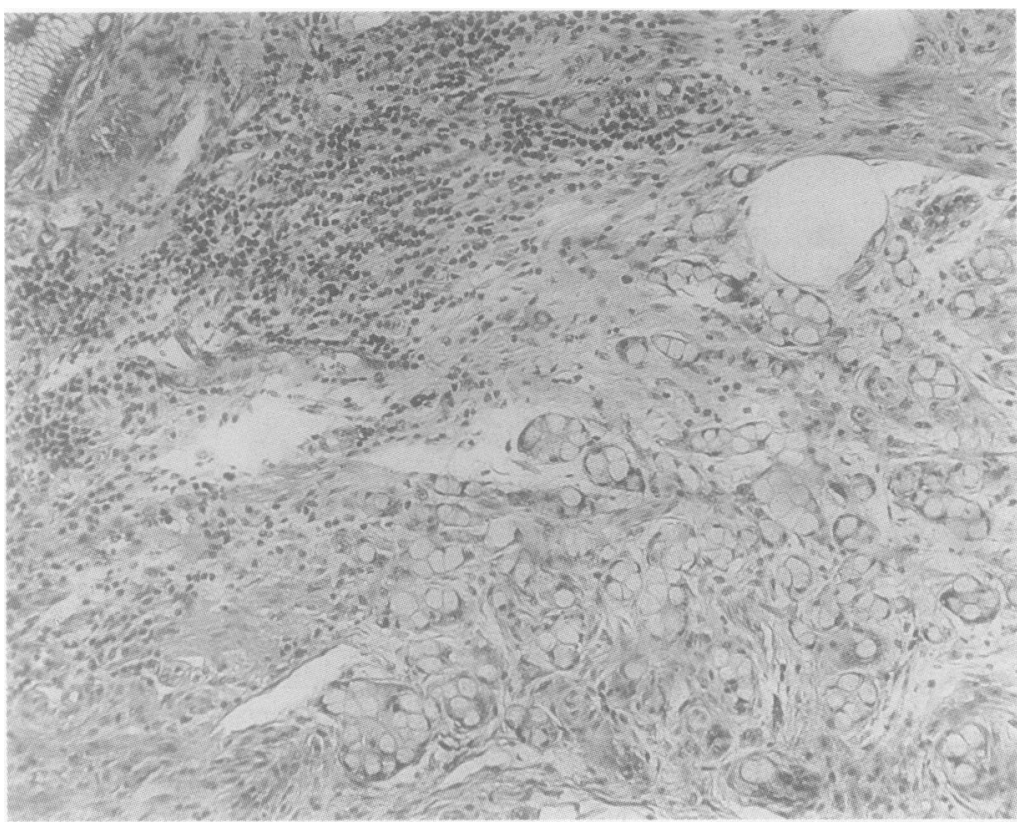

Figure 2 Goblet cell carcinoid nests infiltrating the wall of the appendix (haematoxylin and eosin, $\times 100$ ). endocrine/exocrine cell termed an amphicrine cell, hence the amphicrine cell carcinoma. ${ }^{8}$ The striking resemblance of the tumour nests to intestinal crypts prompted Isaacson to postulate an origin from lysozyme producing cells normally present in intestinal crypts. ${ }^{9}$

Mucinous cystadenoma is the most common cause of the so-called mucocele of the appendix. In this condition there is focal cystic dilatation of the appendix which is lined by columnar/cuboidal, mucus secreting epithelium arranged in variable patterns, ranging from well developed papillary formations projecting into the lumen to a single layer of flat cuboidal cells. ${ }^{3}$ Mucus filled diverticulae of the appendiceal wall are commonly associated with this condition because of increased intraluminal pressure. It is now widely accepted that the mucinous cystadenoma is the appendiceal counterpart of villous adenomas occurring elsewhere in the intestine, differing from the latter only because they are restricted to the appendix. $^{34}$

Despite wide interest, the histogenesis of the goblet cell carcinoid remains controversial, hence the importance of this report. If this tumour is a true member of the carcinoid family, as suggested by Subbuswamy et al, then its co-existence with a mucinous cystadenoma, itself an uncommon epithelial appendiceal neoplasm, would seem to support the unitary stem cell hypothesis. If this tumour, however, is a carcinoma of crypt cell origin rather than a carcinoid, as claimed by Isaacson, ${ }^{9}$ then this combination may represent an example of the adenoma/carcinoma sequence, a widely recognised and accepted concept. ${ }^{10}$ Furthermore, the coincidental occurrence of these two neoplasms cannot be entirely ruled out. Further reports of similar occurrences may explain this unusual association.

relatively good prognosis, which resembled that of carcinoids more than adenocarcinomas, and because the principle cell type in the tumour closely resembled the goblet cells of the intestinal tract. Since then, this tumour has been described by a wide variety of names including mucinous carcinoid, adenocarcinoid, amphicrine cell carcinoma, and crypt cell carcinoma. ${ }^{1}$ This broad nomenclature reflects the identification of goblet cells, Paneth cells and enterochromaffin cells within this tumour, the presence of which has given rise to considerable discussion regarding its histogenesis. As a result, several hypotheses have been proposed. Supporters of the unitary hypothesis suggest that the tumour derives from a single neoplastic intestinal cell, albeit with divergent differentiation. ${ }^{7}$ A second hypothesis suggests that the tumour is the result of the simultaneous, integrated, neoplastic proliferation of several histogenetically different elements. ${ }^{2}$ Other authors suggest that it originates from a combined
1 Berardi RS, Lee SS, Chen HP. Goblet cell carcinoids of the appendix. Surg Gynecol Obstet 1988;167:81-6.

2 Warkel RL, Cooper PH, Helwig EB. Adenocarcinoid, mucin-producing tumour of the appendix. Cancer 1978; 42:2781-93.

3 Higa E, Rosai J, Pizzimbono CA, Wise L. Mucosal hyperplasia, mucinous cystadenoma, and mucinous cyst41.

4 Qizilbash AH. Mucoceles of the appendix; their relationship to hyperplastic polyps, mucinous cystadenomas and cystadenocarcinomas. Arch Pathol 1975;99:548-55.

5 Gagne F, Fortin P, Dufour V, Delage C.Tumeurs de l'appendice associant de carreteres histologique de carcinoide et d'adenocarcinome. Ann Anat Pathol 1969;14:393-406.

6 Subbuswamy SG, Gibbs NM, Ross CF, Morson BC. Goblet cell carcinoid of the appendix. Cancer 1974;34:338-44.

7 Warner TFCS, Seo IS. Goblet cell carcinoid of appendix; ultrastructural features and histogenetic aspects. Cancer 1979;44:1700-6.

8 Olsson B, Ljunberg $O$. Adenocarcinoid of the vermiform appendix. Virchows Arch A Pathol Anat Histopathol 1980; 386:201-10.

9 Isaacson P. Crypt cell carcinoma of the appendix (so-called adenocarcinoid tumour). Am ₹ Surg Pathol 1981;5:213-24.

10 Day DW, Morson BC. The adenoma-carcinoma sequence. In: Morson BC, ed. The pathogenesis of colorectal cancer. Vol 10 in the series Major problems in pathology. Philadelphia: W B Saunders, 1978:58-71. denocarcinoma of the appendix. Cancer 1973;32:1525 